\title{
Persepsi Kebahagiaan Pada Masyarakat Banjar di Desa Gandaraya Kecamatan Anjir Pasar Kabupaten Barito Kuala
}

\author{
Rahmawati, Arni, dan Imadduddin \\ Universitas Islam Negeri Antasari Banjarmasin
}

\begin{abstract}
Happiness is a feeling that can be experienced by everyone, but the way to get happiness varies depending on how the person perceives it. The purpose of this research is to find out how the level and perception of happiness in the Banjar community. This type of research uses a mixed method with 55 people for a quantitative approach and 12 people for a qualitative approach taken from a sample of 55 people who have high levels of happiness. Data collection techniques used were, questionnaire, observation and interview. The results of this study can be concluded that the level of happiness of adolescents with high happiness categories is $35 \%$ and moderate $65 \%$, adults are high happiness categories $55 \%$ and moderate $45 \%$, and elderly happiness categories are high $46.7 \%$ and moderate $53.3 \%$. Perceptions of happiness in adolescents are positive emotions, gratitude, family, achievement, peers, and social life. Adults are positive emotions, be patient and grateful, family, marriage, physical health, money, work, social life, and religiosity. While the elderly are positive emotions, gratitude, age, money, family, physical health, religion, social life.
\end{abstract}

Keywords: Perception; Happiness; Banjar Community; Village.

\begin{abstract}
Abstrak
Kebahagiaan yaitu suatu perasaan yang dapat dialami oleh semua orang, tapi cara untuk mendapatkan kebahagiaan itu berbeda-beda tergantung bagaimana orang tersebut mempersepsikannya. Tujuan dalam penelitian ini adalah untuk mengetahui bagaimana tingkat dan persepsi kebahagiaan pada masyarakat Banjar. Jenis penelitian ini menggunakan metode campuran dengan 55 orang untuk pendekatan kuantitatif dan 12 orang untuk pendekatan kualitatif diambil dari sampel 55 orang yang memiliki tingkat kebahagiaan yang tinggi. Teknik pengumpulan data yang digunakan yaitu, angket, observasi dan wawancara. Hasil penelitian ini dapat disimpulkan bahwa tingkat kebahagiaan remaja kategori kebahagiaan tinggi 35\% dan sedang 65\%, dewasa yaitu kategori kebahagiaan tinggi 55\% dan sedang 45\%, dan lanjut usia kategori kebahagiaan tinggi 46,7\% dan sedang 53,3\%. Persepsi kebahagiaan pada remaja yaitu emosi positif, bersyukur, keluarga, prestasi, teman sebaya, dan kehidupan sosial. Dewasa yaitu emosi positif, bersabar dan bersyukur, keluarga, pernikahan, kesehatan fisik, uang, pekerjaan, kehidupan sosial, dan religiusitas. Sedangkan lanjut usia yaitu emosi positif, bersyukur, usia, uang, keluarga, kesehatan fisik, agama, kehidupan sosial.
\end{abstract}

Kata Kunci: Persepsi; Kebahagiaan; Masyarakat Banjar; Desa. 
Setiap manusia menginginkan hidupnya bahagia. Hal tersebut menjadi harapan terbesar bagi setiap orang baik itu dari usia, tempat tinggal, status sosial, ataupun agama. Kebahagiaan menjadi faktor yang sangat penting dan menjadi tujuan akhir dalam kehidupan seseorang, hidup akan terasa tidak lengkap jika belum merasakan kebahagiaan. Orang dahulu percaya jika kebahagiaan itu bukanlah sesuatu yang dicapai, tapi sebuah anugerah yang diberikan Tuhan kepada hambanya atau sebuah kemurahan hati dari yang maha kuasa (Dea Febri Hapsari, 2015). Kebahagiaan yaitu suatu perasaan yang dapat dialami oleh semua orang, tetapi cara untuk mendapatkan kebahagiaan itu berbeda-beda tergantung bagaimana orang tersebut mempersepsikan kebahagiaan itu (Harmaini dan Alma, 2014). Jadi dari perbedaan persepsi itu ada yang mengatakan apabila sudah memiliki banyak uang maka dapat merasa bahagia, atau akan bahagia apabila sudah memiliki mobil pribadi, ada juga yang mengatakan bahwa bahagia jika mendapatkan segala yang diinginkan.

Aspek psikologi sering menyebut kebahagiaan itu dengan well-being, Menurut Hurlock (1980), kebahagiaan ialah suatu keadaaan sejahtera dan kepuasan hati, yaitu kepuasan yang menyenangkan yang muncul bila kebutuhan dan harapan tertentu seseorang itu telah terpenuhi (Siti dan Rini, 2012). Oleh karena itu, sangat jelas bahwa apabila terpenuhinya kesejahteraan seseorang maka kebahagiaan akan mereka rasakan. Menurut Diener, Scollon dan Lucas, istilah subjective well-bieng (SWB) adalah istilah ilmiah dari happiness (kebahagiaan) yang terbagi atas dua komponen di dalamnya. Kedua komponen tersebut adalah komponen afektif dan komponen kogntif. Istilah tersebut lebih dipilih untuk digunakan oleh ilmuwan, karen istilah happiness sudah diperdebatkan definisinya selama berabad-abad (Diener, Scollon, dan Lucas, 2003).

Seligman (2005) menjelaskan bahwa terdapat dua faktor yang dapat menimbulkan kebahagiaan, yaitu faktor eksternal dan faktor internal. Faktor eksternal yaitu faktor yang berasal dari luar yakni uang, pernikahan, kehidupan sosial, kesehatan, agama, usia, pendidikan, iklim, ras, dan gender. Sedangkan faktor internal yaitu faktor yang berasal dari dalam yakni character strengh atau kekuatan karakter, kepuasan terhadap masa lalu, optimis terhadap masa depan, serta kebahagiaan pada masa sekarang (Husna Sholihah, 2018). 
Budaya yang di dalamnya terdapat konsep tentang nilai-nilai itu memiliki sumbangan terhadap pembentukan konsep psikologi seseorang yang mungkin diperoleh seseorang tersebut secara turun temurun seperti halnya dengan konsep kebahagiaan, menurut Kim dan Park (2006) menyatakan bahwa budaya itu memiliki peranan yang sangat sentral dalam mempersepsikan fenomena sosial yang ada dilingkungan kita. Oleh sebab itu, dapat kita pahami bahwa jika suatu nilai kebahagiaan seseorang itu dipengaruhi oleh konteks budaya yang berlaku (Hermaini dan Alma, 2014).

Pada beberapa tahun belakangan ini semakin banyak penelitian yang dilakukan untuk mengetahui tingkat kebahagiaan penduduk Negara-negara di dunia. Data negara paling bahagia di dunia telah di rilis World Happiness Report. Terdapat 10 negara paling bahagia dengan urutan pertama diperoleh oleh Finlandia. Bagaimana dengan Indonesia? Di tahun 2019 Indonesia memperoleh posisi 92 dari 156 negara. Di mana posisi ini lebih unggul di bandingkan negara China dan Vietnam (Syanti Mustika, 2019).

Ada dua survei yang dilakukan menunjukkan bahwa Negara Indonesia memiliki tingkat kebahagiaan yang relatif tinggi karena lebih unggul dari setengah negara lainnya (Herlani dan Five, 2010). Ada juga beberapa penelitian yang dilakukan di Indonesia dari penelitian yang dilakukan oleh Herlani dan Fivi tentang kekuatan karakter dan kebahagiaan pada Suku Jawa, dari hasil penelitian tersebut menunjukkan bahwa terdapat hubungan antara kekuatan karakter dan kebahagiaan pada Suku Jawa, tingkat kebahagiaan orang Jawa mayoritas berada pada tingkat tinggi (Wijayanti dan Nurwianti, 2010). Penelitian yang dilakukan oleh Sari dan Fifi tentang kekuatan karakter dan kebahagiaan pada Suku Minang, hasil dari penelitian tersebut menunjukkan terdapat hubungan yang signifikan antara kekuatan karakter dan kebahagiaan (Sari dan Fivi).

Di Indonesia ada berbagai macam suku menurut data statistik di Indonesia ada terdapat 1.331 suku (BPS, 2015), khususnya di pulau Kalimantan ada sebanyak 10 suku, salah satu suku yang terbesar di pulau Kalimantan adalah suku Banjar. Suku Banjar atau juga disebut dengan orang Banjar adalah penduduk asli dari daerah kota Banjarmasin. Daerah tersebut bertambah luas sampai ke kota Martapura, ibukota Kabupaten Banjar, dan wilayah sekitarnya. Bahasa yang digunakan oleh pendudukan di daerah tersebut adalah bahasa Banjar (Alfani Daud, 1997). 
Salah satu Kabupaten yang memiliki banyak suku Banjar adalah Kabupaten Barito Kuala sekitar 184.180 jiwa, khususnya di Kecamatan Anjir Pasar Desa Gandaraya, hal ini sesuai dengan wawancara yang dilakukan oleh peneliti kepada salah satu staf di Kecamatan mengatakan bahwa Suku Banjar yang ada di Kecamatan Anjir Pasar sekitar 90\%. Terkait dengan penelitian yang akan dilakukan oleh peneliti, alasannya karena selama ini belum ada yang mencoba mengaitkan antara kebahagiaan dengan masyarakat yang bersuku Banjar atau peneliti belum menemukan penelitian tentang kebahagiaan pada masyarakat Banjar.

Berdasarkan latar belakang tersebut, maka peneliti tertarik untuk membahas dan mengkaji lebih dalam tentang bagaimana persepsi dari remaja, orang dewasa, dan yang berusia lanjut dari masyarakat Banjar tentang kebahagiaan, yang akan dituangkan dalam skripsi yang berjudul "Persepsi Kebahagiaan Pada Masyarakat Banjar Di Desa Gandaraya Kecamatan Anjir Pasar Kabupaten Barito Kuala".

\section{Metode}

Jenis penelitian ini adalah penelitian lapangan (field reseach) yang menggunakan informasi yang diperoleh dari lapangan secara langsung (Rahmadi, 2011), yang berkenaan dengan persepsi kebahagiaan suku Banjar. Pendekatan yang digunakan dalam penelitian ini adalah pendekatan mixed methods (metode campuran). Pendekatan metode campuran adalah rangkaian pendekatan kuantitatif dan kualitatif dalam suatu metodologi penelitian pada kajian tunggal ataupun kajian beragam tahapan (Abbas dan Charles, 2010). Teknik yang digunakan yaitu teknik purposeful sampling yang berdasarkan pada ciri-ciri yang dimiliki oleh subjek yaitu subjek remaja yang berusia (13-18), dewasa awal yang berusia (18-40), dan lanjut usia yang berusia (60 ke atas), bersuku Banjar, ayah dan ibu asli orang Banjar, berbahasa Banjar, dan beragama Islam dengan 55 orang untuk pendekatan kuantitatif dan 12 orang untuk pendekatan kualitatif diambil dari sampel 55 orang yang memiliki tingat kebahagiaan yang tinggi. Teknik pengumpulan data yang digunakan yaitu, angket, observasi dan wawancara. 


\section{Hasil}

Dari 55 sampel dari remaja, dewasa, dan usia lanjut di Desa Gandaraya diperoleh data keseluruhan yang terbagi menjadi 3 kategori, yaitu tinggi, sedang, dan rendah. Berikut hasilnya:

Tabel 1

Kategorisasi Variabel Kebahagiaan Keseluruhan

\begin{tabular}{ccc}
\hline Kategorisasi & Jumlah & Persentase \\
\hline Tinggi $\mathbf{1 2 0} \leq \mathbf{X}$ & 25 & $54,5 \%$ \\
Sedang $\mathbf{8 0} \leq \mathbf{X}<\mathbf{1 2 0}$ & 30 & $45,5 \%$ \\
Rendah $\mathbf{X}<\mathbf{8 0}$ & 0 & $0 \%$ \\
Jumlah & $\mathbf{5 5}$ & $\mathbf{1 0 0 \%}$ \\
\hline
\end{tabular}

Dari 55 sampel, 20 sampel dari remaja diperoleh data keseluruhan yang terbagi menjadi 3 kategori, yaitu tinggi, sedang, dan rendah. Berikut hasilnya:

Tabel 2

Kategorisasi Varibel Kebahagiaan Remaja

\begin{tabular}{ccc}
\hline Kategorisasi & Jumlah & Persentase \\
\hline Tinggi $\mathbf{1 2 0} \leq \mathbf{X}$ & 7 & $35 \%$ \\
Sedang $\mathbf{8 0} \leq \mathbf{X}<\mathbf{1 2 0}$ & 13 & $65 \%$ \\
Rendah $\mathbf{X}<\mathbf{8 0}$ & 0 & $0 \%$ \\
Jumlah & $\mathbf{2 0}$ & $\mathbf{1 0 0} \%$ \\
\hline
\end{tabular}

Dari 55 sampel, 20 sampel dari remaja diperoleh data keseluruhan yang terbagi menjadi 3 kategori, yaitu tinggi, sedang, dan rendah. Berikut hasilnya: 
Tabel 3

Kategorisasi Varibel Kebahagiaan Dewasa

\begin{tabular}{ccc}
\hline Kategorisasi & Jumlah & Persentase \\
\hline Tinggi $\mathbf{1 2 0} \leq \mathbf{X}$ & 11 & $55 \%$ \\
Sedang $\mathbf{8 0} \leq \mathbf{X}<\mathbf{1 2 0}$ & 9 & $45 \%$ \\
Rendah $\mathbf{X}<\mathbf{8 0}$ & 0 & $0 \%$ \\
Jumlah & $\mathbf{2 0}$ & $\mathbf{1 0 0} \%$ \\
\hline
\end{tabular}

Dari 55 sampel, 15 sampel dari remaja diperoleh data keseluruhan yang terbagi menjadi 3 kategori, yaitu tinggi, sedang, dan rendah. Berikur hasilnya:

Tabel 4

Kategorisasi Varibel Kebahagiaan Usia Lanjut

\begin{tabular}{ccc}
\hline Kategorisasi & Jumlah & Persentase \\
\hline Tinggi $\mathbf{1 2 0} \leq \mathbf{X}$ & 7 & 46, \\
& & $7 \%$ \\
Sedang $\mathbf{8 0} \leq \mathbf{X}<\mathbf{1 2 0}$ & 8 & 53, \\
& & $3 \%$ \\
Rendah $\mathbf{X}<\mathbf{8 0}$ & 0 & $0 \%$ \\
Jumlah & $\mathbf{1 5}$ & $\mathbf{1 0 0 \%}$ \\
\hline
\end{tabular}

Dari 55 sampel dari remaja, dewasa, dan usia lanjut di Desa Gandaraya diperoleh data keseluruhan yang terbagi menjadi 3 kategori, yaitu tinggi, sedang, dan rendah. Berikut hasilnya 
Tabel 5

Kategorisasi Varibel Kebahagiaan Dari Usia Remaja, Dewasa, Dan Lanjut Usia

\begin{tabular}{clll}
\hline Kategorisasi & Remaja & Dewasa & Lanjut Usia \\
\hline Tinggi $\mathbf{1 2 0} \leq \mathbf{X}$ & $35 \%$ & $55 \%$ & $46,7 \%$ \\
Sedang $\mathbf{8 0} \leq \mathbf{X}<\mathbf{1 2 0}$ & $65 \%$ & $45 \%$ & $53,3 \%$ \\
Rendah $\mathbf{X}<\mathbf{8 0}$ & $0 \%$ & $0 \%$ & $0 \%$ \\
Jumlah & $\mathbf{2 0}$ & $\mathbf{1 0 0} \%$ & $\mathbf{1 5}$ \\
\hline
\end{tabular}

Berdasarkan hasil wawancara, persepsi kebahagiaan pada remaja, dewasa, dan lanjut usia memiliki perbedaan. Pada kategori remaja yaitu menurut subjek MR kebahagiaan itu ketika di sayang orang tua, membahagiakan orang tua, berprestasi seperti dapat rangking, dan nilai yang bagus, berkumpul dengan teman sebaya, dan bersyukur. Menurut subjek H kebahagiaan itu jika berprestasi seperti dapat nilai yang tinggi, mendapat kejuaraan atau menang dalam perlombaan, membahagiakan orang tua, bersyukur, berkumpul dengan keluarga dan teman sebaya, dapat menolong orang lain, dan keinginan tercapai. Sedangkan menurut subjek F kebahagiaan itu jika disayang orang tua, membahagiakan orang tua, berprestasi seperti dapat rangking, dan nilai yang tinggi, cita-cita tercapai, berkumpul dengan orang tua, kakek nenek, dan teman sebaya, bersyukur, dan dapat menolong orang lain. Sama halnya juga dengan subjek LS menjelaskan bahwa kebahagiaan itu jika mempunyai banyak teman, keluarga yang harmonis, membahagiakan orang tua, berprestasi seperti dapat rangking, dapat mencapai citacita, bersyukur, dapat membantu orang lain, dan tidak ada masalah di sekolah.

Pada kategori dewasa menurut subjek $\mathrm{H}$ kebahagiaan itu yang berhubungan dengan keluarga, keuangan, dalam hal rezeki walaupun sedikit tetapi berkah, kesehatan, berkumpul dengan orang tua, suami, dan anak, membahagiakan orang tua, suami, dan anak, dapat mendidik anak dengan baik dan bersyukur, bersabar, dan dapat membantu orang lain. Menurut subjek $\mathrm{N}$ kebahagiaan itu jika dapat menikmati hidup, bersyukur, merasa tenang dan damai jika melakukan ibadah, membahagiakan dan membanggakan keluarga, orang tua, suami, dapat mencapai cita-cita, dapat membantu orang lain, kesehatan, dan pekerjaan. Selain 
itu juga menurut subjek $\mathrm{AH}$ kebahagiaan itu yang berhubungan dengan keluarga, teman sebaya, membahagiakan orang tua, bersyukur, dapat membantu orang lain, merasa tenteram, damai, dan tenang, pekerjaan, keinginan tercapai, dan tidak ada masalah. Sama halnya juga dengan subjek W menurutnya kebahagiaan itu jika mempunyai banyak uang, berkumpul keluarga, teman sebaya, membahagiakan orang tua, bersyukur, dapat membantu orang lain, kesehatan agar dapat bekerja, dan beribadah.

Sedangkan dari kategori lanjut usia menurut subjek K kebahagiaan itu adalah yang juga berhubungan dengan keluarga, anak dan cucu, kesehatan agar dapat beribadah, panjang umur agar dapat menuntut ilmu dan beribadah, pekerjaan walaupun petani tetap bersyukur, membahagiakan keluarga, dan teman sebaya, dapat membantu orang lain, dan tidak merasa gelisah. Menurut subjek M kebahagiaan itu jika badan sehat, tidak ada masalah, senang, pekerjaan walaupun petani tetap bersyukur, keuangan, beribadah, merasa tenang, bersilaturahmi dengan keluarga dan teman-teman, membahagiakan anak dan cucu, dan dapat membantu orang lain. Menurut subjek B juga bahwa kebahagiaan itu yang berhubungan dengan keluarga, anak dan cucu, kesehatan agar dapat menuntut ilmu dan beribadah, keuangan, masalah rezeki berkecukupan agar dapat menuntut ilmu dan beribadah, bersyukur, pikiran tenang, tidak ada masalah, dapat membantu orang lain, dan dapat berkumpul dengan teman sebaya. Sama halnya juga dengan subjek $H$ menurutnya kebahagiaan itu yang berhubungan dengan keluarga, anak dan cucu, kesehatan, keinginan tercapai, pekerjaan, tidak ada masalah dalam pikiran, bersyukur, berkumpul dengan teman sebaya menghilangkan pikiran yang tidak baik, dapat membantu orang lain, mengingat Allah, dan beribadah.

\section{Pembahasan}

Berdasarkan hasil penelitian, tingkat kebahagiaan keseluruhan dari remaja, dewasa, dan usia lanjut yaitu kategori kebahagiaan tinggi dari jumlah 55 orang sebesar 54,5\%, dan sedang 45,5\%. Untuk tingkat kebahagiaan remaja dari jumlah 20 orang kategori kebahagiaan tinggi sebesar 35\% dan sedang 65\%. Tingkat kebahagiaan dewasa dari jumlah 20 orang yaitu kategori kebahagiaan tinggi 55\% dan sedang 45\%. Dan tingkat kebahagiaan lanjut usia kategori kebahagiaan tinggi 46,7\% dan sedang 8 53,3\%. Kebahagiaan yang dirasakan oleh remaja, 
dewasa, dan lanjut usia di Desa Gandaraya secara keseluruhan dan berdasarkan kategori usia termasuk ke dalam kategori sedang.

Berdasarkan hasil wawancara, persepsi kebahagiaan pada remaja, dewasa, dan lanjut usia memiliki perbedaan. Menurut Jalaluddin Rakhmat persepsi adalah pengalaman tentang objek, peristiwa, atau hubungan-hubungan yang diperoleh dengan menyimpulkan informasi dan menafsirkan pesan. Persepsi yaitu memberikan makna pada stimuli inderawi (sensory stimuli) (Jalaluddin Rakhmat, 2008). Penelitian yang dilakukan peneliti mengacu pada konsep kebahagiaan Diener dan Ryff yang menunjukkan bahwa terdapat tiga aspek kebahagiaan, yaitu aspek kognitif, aspek afektif dan aspek perilaku. Menurut Diener aspek kognitif pada kebahagiaan merupakan kepuasan di berbagai bidang kehidupan, kebahagiaan dapat muncul disebabkan oleh kepuasan pada diri sendiri, keluarga, teman sebaya, kesehatan, keuangan, pekerjaan, dan waktu luang (Diener, 2000).

Pada kategori remaja, keempat subjek cenderung memiliki kesamaan persepsi tentang kebahagiaan secara aspek kognitif yaitu dari subjek MR, Subjek H, subjek F, dan subjek LS. Pada kategori ini lebih cenderung berhubungan dengan orang tua, seperti disayang orang tua, dapat membahagiakan dan membanggakan kedua orang tua, kemudian keluarga. Hal tersebut sesuai dengan teori yang di kemukakan oleh Hurlock bahwa kasih sayang adalah hal yang normal yang dialami manusia, kasih sayang muncul dari sikap diterima oleh orang lain, semakin diterima baik oleh orang lain, semakin banyak kasih sayang diharapkan dari orang lain. Jadi semakin banyak kasih sayang yang dirasakan, maka semakin banyak pula kebahagiaan yang dialami seseorang (Hurlock, 1980). Hal lainnya ialah prestasi atau pencapaian pribadi seperti mendapat nilai yang tinggi, rangking dan mendapat kejuaraan atau perlombaan dan mencapai cita-cita. Sesuai dengan teori dari Hurlock bahwa prestasi merupakan salah satu indikator tercapainya tujuan seseorang. Kebahagiaan akan tercipta sejalan dengan prestasi yang diraihnya (Hurlock, 1980). Selain itu juga yang berhubungan dengan hubungan sosial seperti teman sebaya.

Pada kategori dewasa dari keempat subjek yaitu subjek $\mathrm{H}$, subjek B, subjek $\mathrm{AH}$, dan subjek W lebih cenderung yang berhubungan dengan keluarga yaitu orang tua, mertua, pernikahan yaitu suami atau istri dan anak, kesehatan, keuangan yaitu berkecukupan dalam 
hal rezeki, dan yang berhubungan dengan hubungan sosial seperti berkumpul dan berbaur dengan teman-teman atau masyarakat yang ada di desa. Hal ini sesuai dengan nilai budaya Banjar pada konsepsi bisa-bisa maandak awak untuk menyesuaikan diri dengan lingkungan (Ermina Istiqomah, 2014).

Sedangkan pada kategori lanjut usia dari ke empat subjek yaitu subjek $\mathrm{K}$, subjek $\mathrm{M}$, subjek B, dan subjek $H$ persepsi kebahagiaan secara aspek kognitif ialah kesehatan seperti badan sehat, tidak ada masalah, keluarga yaitu ada anak dan cucu, waktu luang yaitu dapat berkumpul dengan keluarga, pekerjaan seperti petani tetapi tetap bersyukur, keuangan seperti rezeki dimudahkan dan berkecukupan, apa yang diinginkan terkabul atau tercapai dan menerima apa adanya, hubungan sosial yaitu teman sebaya dan pada usia lanjut sebagian dari mereka tidak bisa bekerja lagi karena sudah tidak kuat, dan hanya ingin menuntut ilmu serta dipanjangkan umur agar dapat beribadah.

Aspek afektif yaitu persepsi kebahagiaan dari reaksi seseorang terhadap peristiwa yang terjadi dalam hidup yang meliputi emosi (afek) yang menyenangkan dan emosi yang tidak menyenangkan (Diener, 2003). Aspek afektif terbagi dua yaitu afek positif dan afek negatif, afek positif yaitu perasaan tenang, bersyukur, hidup penuh damai sejahtera, nikmat, tenteram, dan perasaan positif seperti kasih sayang. Dan afek negatif yaitu perasaan marah, benci, jijik, rasa bersalah, ketakutan dan kegelisahan (Watson, Clark, dan Tellegen, 1998).

Berdasarkan hasil wawancara, persepsi kebahagiaan dari aspek afektif atau emosi pada kategori remaja, menurut keempat subjek ialah mereka bahagia dalam menjalani hidupnya sekarang dan lebih sering merasa bahagia karena disayang orang tua, punya banyak teman di desa atau di sekolah, berkumpul dengan teman-teman dan keluarga, dapat nilai yang bagus, tidak ada masalah dan mereka menerima dan mensyukuri apa yang ada dalam dirinya. Yang dikhawatirkan remaja ialah jika apa yang dinginkan itu tidak tercapai, jika ada PR di sekolah dan tidak mendapatkan nilai yang bagus. Hal ini sesuai dengan penelitian yang dilakukan oleh Hermaini dan Alma yang berjudul peristiwa-peristiwa yang membuat bahagia, hasil dari penelitian tersebut ada tiga komponen besar yang membuat remaja bahagia, yaitu pertama peristiwa yang berhubungan dengan orang tua, keluarga, dan teman sebaya. Kedua peristiwa yang berhubungan dengan lawan jenis kelamin, mendapatkan kasih sayang, hobi dan lain-lain. 
Yang ketiga peristiwa yang berhubungan dengan prestasi, kelulusan, mampu menyelesaikan tugas, dan hasil yang memuaskan (Harmaini dan Alma, 2014).

Persepsi kebahagiaan dari aspek afektif pada kategori dewasa berdasarkan hasil wawancara didapat bahwa mereka merasa bahagia dalam menjalani kehidupan sekarang dan lebih sering merasa bahagia pada setiap keadaan, baik itu susah maupun senang, karena dalam hal rezeki berkecukupan, sehat badan dapat bekerja, sesuai dengan apa yang diharapkan. Persepsi kebahagiaan usia dewasa juga berhubungan dengan keluarga, hidupnya damai jika dapat berkumpul dengan keluarga atau teman-teman, menerima dan mensyukuri apapun yang ada dalam dirinya. Yang dikhawatirkan dari dewasa ialah jika sakit, apa yang diinginkan tidak terdapat berkaitan dengan pekerjaan takut apabila diberhentikan dari pekerjaan, tidak bisa beribadah, tidak bisa membahagiakan orang tua dan takut membuat orang tua kecewa, dan sesuatu hal lain yang tidak dinginkan terjadi pada keluarganya misalnya orang tua, pasangan atau anak.

Pada kategori lanjut usia persepsi kebahagiaan secara aspek afektif dari keempat subjek ialah mereka merasa senang dalam menjalani kehidupan sekarang dan lebih sering merasa bahagia, karena mensyukuri apa adanya, tidak merasa gelisah sebab ada keluarga anak dan cucu, pikiran tenang, damai, tenteram, tidak ada masalah, contohnya yang membuat lanjut usia merasa bahagia jika uang tetap ada jadi merasa tenang, anak dan cucuk semuanya baik mengingatkan masalah ibadah dan menjalankan syariat agama, selain itu bersilaturahmi dengan teman-teman dan keluarga. Hal ini sesuai dengan unsur domain Orang Banjar, yaitu dari segi keberagamaannya adalah Islam (Ermina Istiqomah, 2014). Yang dikhawatirkan atau dicemaskan oleh lanjut usia ialah jika sakit tidak bisa melakukan apa-apa seperti beribadah, dan keluarga jangan sampai terjerumus kepada hal-hal yang tidak baik. Hal ini sesuai dengan Penelitian yang dilakukan oleh Ahmad Muhammad Diponegoro dan Mulyono yang meneliti tentang faktor-faktor psikologis yang mempengaruhi kebahagiaan pada lanjut usia Suku Jawa di Klaten, hasil penelitian faktor yang mempengaruhi kebahagiaan lanjut usia yaitu penghasilan, usia, agama, budaya, bersyukur kepada Tuhan, aktivitas fisik, hubungan sosial, memaafkan, kualitas hidup, silaturahmi, sehat, berhubungan baik dengan anak, cucu, dan menantu, serta berhubungan baik dengan saudara, dan merasa senang, suasana tenang, 
optimis, senang menolong/memberi, dan tidak takut meninggal/pasrah kepada takdir di usia tua (Diponegoro dan Mulyono, 2015).

Dari kategori remaja, dewasa dan lanjut usia mempunyai kesamaan pendapat bahwa mereka menerima apa yang ada di dalam diri dan mensyukurinya, ini sesuai dengan nilai budaya pada Suku Banjar dalam hubungan manusia dengan Tuhan meliputi ikhlas dan syukur dengan konsep nilai berelaan. Banjar mempunyai unsur domain, yaitu dari segi bahasa, yaitu bahasa Banjar dan dari segi keberagamaannya adalah Islam. Salah satu nilai budaya suku banjar yaitu Ikhlas dan syukur dengan menekankan konsep berelaan dan semata-mata untuk ibadah dan mendapat keridhoan Allah SWT (Ermina Istiqomah, 2014).

Dalam Alquran manusia diperintahkan untuk bersyukur atas nikmat yang diberikan Allah sebagaimana yang terkandung dalam Qur'an surah Al-Baqarah ayat 172 :

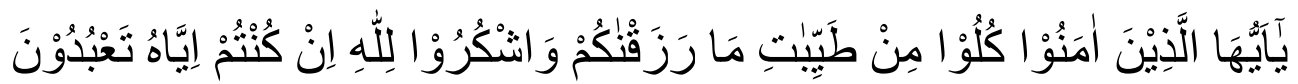

"Hai orang-orang yang beriman, makanlah di antara rezki yang baik-baik yang Kami berikan kepadamu dan bersyukurlah kepada Allah, jika benar-benar kepada-Nya kamu menyembah" (QS. Al-Baqarah, 2:172)

Ayat Al-Baqarah ayat 172 menjelaskan bahwa kita harus bersyukur atas apa yang diberikan Tuhan kepada kita. Gratitude (bersyukur) adalah suatu perilaku atau sikap batin yang sangat penting karena bisa membangkitkan emosi positif yang sangat kuat, yang bisa memicu perubahan dan perkembangan positif yang sangat luar biasa, dan pada akhirnya hal tersebut memiliki kontribusi pada kebahagiaan (Iman Setiadi Arif, 2016).

Aspek perilaku terbagi menjadi dua, yaitu sosial dan religius. Persepsi kebahagiaan yang berorientasi pada nilai-nilai sosial seperti dapat membantu dan memberi dukungan terhadap sesama, bermanfaat untuk orang lain dan keluarga. Dan religius seperti dekat dengan Tuhan, rasa tidak ada beban atau masalah, dan mengamalkan ajaran-Nya.

Berdasarkan hasil wawancara, pada kategori remaja dari keempat subjek persepsi kebahagiaan dari aspek perilaku berhubungan dengan nilai-nilai sosial yaitu berteman dengan teman sebaya yang ada di desa ataupun di sekolah, suka mempunyai banyak teman karena jika mempunyai banyak teman menyenangkan, dan remaja menyukai teman yang baik, pintar, suka menolong dan lucu. Selain itu juga orang yang ingin dibahagiakan remaja ialah orang tua, cara 
remaja agar dapat membahagiakan orang tua ialah dengan berprestasi di sekolah seperti mendapat rangking, dapat mencapai cita-cita, dapat membantu orang lain atau saling tolong menolong, dan yang berhubungan dengan religius yaitu jika menjalankan agama secara baik seperti beribadah maka akan merasakan kebahagiaan hidup dan dapat ketenangan batin.

Pada kategori dewasa keempat subjek persepsi kebahagiaan dari aspek perilaku yang berhubungan dengan nilai-nilai sosial orang dewasa suka mempunyai banyak teman yang sebaya karena menurut mereka jika mempunyai banyak teman itu dapat berbagi cerita dalam keadaan susah ataupun senang, dan dapat saling bantu. Orang yang ingin dibahagiakan ialah orang tua, pasangan dan anak. Jika dapat membantu orang lain yang ada di desa mereka merasa bahagia karena hidup terasa bermanfaat, dalam hal religius menurut keempat subjek jika orang lain atau mereka sendiri dapat menjalankan agama atau beribadah secara baik seperti shalat dengan khusyuk, membaca Al-qur'an, dan menjauhi hal-hal yang tidak bermanfaat atau menggunjing orang lain, maka akan merasakan ketenangan, ketenteraman, damai dan kebahagiaan hidup.

Sedangkan persepsi kebahagiaan pada kategori lanjut usia juga berhubungan dengan sosial seperti suka mempunyai banyak teman dan berkumpul dengan teman sebaya karena menurut subjek lanjut usia dapat menghilangkan pikiran yang tidak baik, menyukai teman yang baik, suka membimbing dan mengajak ke jalan yang benar atau hal-hal yang baik, jujur tidak bisa menggunjing orang, tahu sopan santun. Subjek lanjut usia bahagia jika dapat membantu orang lain atau warga yang ada di desa, orang yang ingin dibahagiakan subjek lanjut usia ialah keluarga anak dan cucu, karena ketika sudah tua siapa lagi yang merawat, sayang dengan anak cucu semuanya, yang dekat dan mudah untuk diajak berbicara. Dan dalam hal religius menurut subjek lanjut usia jika menjalankan ibadah secara baik maka akan merasakan kebahagiaan hidup contohnya jika dapat membagi ilmu dengan orang lain, menjalankan ibadah dengan khusyuk, menuntut ilmu bisa pergi ke majelis ilmu atau majelis zikir, menjauhi apa yang dilarang dan melakukan kebaikan-kebaikan dalam agama, maka akan merasa tenang dan merasa bahagia.

Dari kategori usia remaja, dewasa dan lanjut usia mempunyai persamaan pendapat dalam hal suka saling tolong menolong yang sesuai dengan nilai budaya yang ada di Suku 
Banjar dalam hubungan manusia dengan manusia meliputi nilai musyawarah, persaudaraan, gotong royong, tolong menolong, penyesuaian diri dengan konsep nilai bubuhan, bedingsanakan, betutulungan, bakalah bamanang. Menurut Soekanto (2004), konsep bubuhan termuat nilai bedingsanakan (persaudaraan), betulungan (tolong menolong) dan mau haja bakalah bamanang (mau saja kalah menang), maksudnya mau saja memberi dan menerima. Hal ini sesuai dengan salah satu keinginan utama manusia, yaitu keinginan untuk menjadi satu dengan manusia lain di sekelilingnya atau masyarakat (Ermina Istiqomah, 2014).

\section{Kesimpulan}

Berdasarkan hasil penelitian yang dilakukan, didapatkan data untuk menjawab tujuan penelitian ini, yakni mengidentifikasi tingkat kebahagiaan dan persepsi kebahagiaan pada masyarakat Banjar di Desa Gandaraya Kecamatan Anjir Pasar Kabupaten Barito Kuala dengan kategori usia yaitu remaja, dewasa, dan lanjut usia, dari hasil analisis data yang diperoleh dalam penelitian ini, dapat disimpulkan bahwa. Tingkat kebahagiaan masyarakat Banjar di Desa Gandaraya yang berusia remaja, kategori kebahagiaan tinggi sebesar 35\% dan sedang 65\%. Tingkat kebahagiaan masyarakat Banjar di Desa Gandaraya yang berusia dewasa, kategori kebahagiaan tinggi sebesar 55\% dan sedang 45\%. Tingkat kebahagiaan masyarakat Banjar di Desa Gandaraya yang berusia lanjut usia, kategori kebahagiaan tinggi sebesar 46,7\% dan sedang 53,3\%. Persepsi kebahagiaan masyarakat Banjar di Desa Gandaraya yang berusia remaja. Yaitu emosi positif dan bersyukur, keluarga, prestasi, teman sebaya, dan kehidupan sosial. Persepsi kebahagiaan pada masyarakat Banjar di Desa Gandaraya yang berusia dewasa. yaitu emosi positif, bersabar dan bersyukur, keluarga, pernikahan, kesehatan fisik, uang, pekerjaan, kehidupan sosial, dan agama/religiusitas. Sedangkan persepsi kebahagiaan masyarakat Banjar di Desa Gandaraya yang berusia lanjut. Ialah emosi positif dan bersyukur, usia, uang, keluarga, kesehatan fisik, agama/religiusitas, dan kehidupan sosial.

\section{Saran}

Saran-saran yang diberikan peneliti yaitu bagi subjek penelitian dari kategori usia remaja, dewasa, ataupun lanjut usia agar tetap terus meningkatkan rasa syukur dalam menjalani 
kehidupan agar dapat merasakan kebahagiaan. Bagi peneliti selanjutnya agar dapat menyeimbangkan jumlah subjek dari remaja, dewasa, dan lanjut usia, dan dapat membangun hubungan dan komunikasi terlebih dahulu dengan subjek penelitian, dan agar lebih menggali sumber keislaman terkait kebahagiaan. Penelitian ini mencari tingkat kebahagiaan dan persepsi kebahagiaan masyarakat Banjar di Desa. Oleh karena itu disarankan kepada peneliti selanjutnya yang ingin meneliti mengenai persepsi kebahagiaan pada masyarakat Banjar agar meneliti di perkotaan. Sehingga nantinya akan diperoleh persepsi kebahagiaan pada masyarakat Banjar di perkotaan.

\section{Referensi}

Abbas Tashakkori, dan Charles Teddle. Mixed Methodology: Mengkombinasikan Pendekatan Kualitatif dan Kuantitatif. Cetakan 1. Yogyakarta: Pustaka Pelajar, 2010.

Akmal, Sari Zakiah, dan Fivi Nurwianti. "Kekuatan Karakter dan Kebahagiaan Pada Suku Minang," t.t.

Arif, Iman Setiadi. Psikologi positif: pendekatann sentifik menuju kebahagiaan. Jakarta: Gramedia Pustaka Utama, 2016.

BPS. "Mengulik Data Suku di Indonesia," 2015. https://www.bps.go.id/news/2015/11/18/127/mengulik-data-suku-di-indonesia.html.

Daud, Alfani. Islam Dan Masyarakat Banjar Diskripsi Dan Analisa Kebudayaan Banjar. Jakarta: PT Raja Grafindo Persada, 1997.

Dea Febri Hapsari. "Hubungan Antara Religiustas Dengan Kebahagiaan Pasa Siswa Siswi Di SMA Muhammadiyah 1 Klaten." Skripsi, Fakultas Psikologi Universitas Muhammadiyah Surakarta, 2015.

Diener, Ed, Christie Napa Scollon, dan Richard E. Lucas. “The Evolving Concept of Subjective Well-Being: The Multifaceted Nature of Happiness" Vol. 15 (2003).

Diponegoro, Ahmad Muhammad, dan Mulyono. "Faktor-faktor Psikologi yang Mempengaruhi Kebahagiaan pada Lanjut Usia Suku Jawa Di Klaten.” PSIKOPEDAGOGIA Vol. 4, No. 1 (2015).

Ed Diener. "Subjective Well-Bieng: The Science of Happiness and a Proposal for a National Index" Vol. 55, No. 1 (Januari 2000): 34-43.

Ermina Istiqomah. "Nilai Budaya Masyarakat Banjar Kalimantan Selatan: Studi Indigenous." Jurnal Psikologi Teori dan Terapan Vol. 5, No. 1 (2014).

Harmaini, dan Alma Yulianti. "Peristiwa-Peristiwa Yang Membuat Bahagia.'” Jurnal Imliah Psikologi Vol. 1, No. 2, (Juni 2014): 109.

Hurlock, Elizabeth B. Psiklologi Perkembangan. Edisi Kelima. Jakarta: Erlangga, 1980.

Mustika, Syanti. “Daftar Negara Paling Bahagia di Dunia 2019, Indonesia Nomor Berapa?" Diakses 26 November 2019. https://travel.detik.com/travel-news/d-4477708/daftar-negarapaling-bahagia-di-dunia-2019-indonesia-nomor-berapa. 
Nurhidayah, Siti, dan Rini Agustini. “'Kebahagiaan Lansia Di Tinjau Dari Dukungan Social Dan Spiritual'," Vol. 5, No. 2, (September 2012): 16.

Rahmadi. Pengantar Metodelogi Penelitian. Banjarmasin: Antasari Press, 2011.

Rakhmat, Jalaluddin. Psikologi Komunikasi. Bandung: PT REMAJA ROSDAKARYA, 2008.

Sholihah, Husna. "Hubungan Kekuatan Karakter Dengan Kebahagiaan Pada Remaja." Skripsi, Fakultas Psikologi dan Kesehatan UIN Sunan Ampel Surabaya, 2018.

Watson, D., L.A Clark, dan Tellegen. "Development and Validation of Brief Measures of Positive and Negative Affect: The PANAS scales." Journal of Personality and Social Psychology Vol. 54, No. 6 (1998).

Wijayant, Herlani, dan Five Nurwianti. "'Kekuatan Karakter Dan Bahagia Suku Jawa,.'” Jurnal Pskologi Vol. 3, No. 2 (Juni 2010): 115.

\begin{tabular}{|l|l|l|l|l|}
\hline Submit & Review & Revisi & Diterima & Publis \\
\hline $25-02-2020$ & - & - & $03-02-2021$ & $30-03-2021$ \\
\hline
\end{tabular}

Rahmawati, Arni, dan Imadduddin

Program Studi Psikologi Islam

Fakultas Ushuluddin dan Humaniora

Universitas Islam Negeri Antasari Banjarmasin

E-mail: $\underline{\text { rahmawatipi68@gmail.com }}$ 